
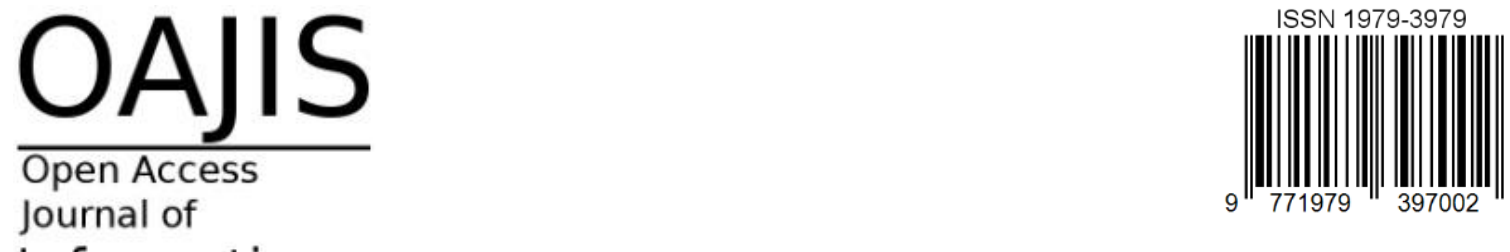

Information

Systems

is.its.ac.id/pubs/oajis/

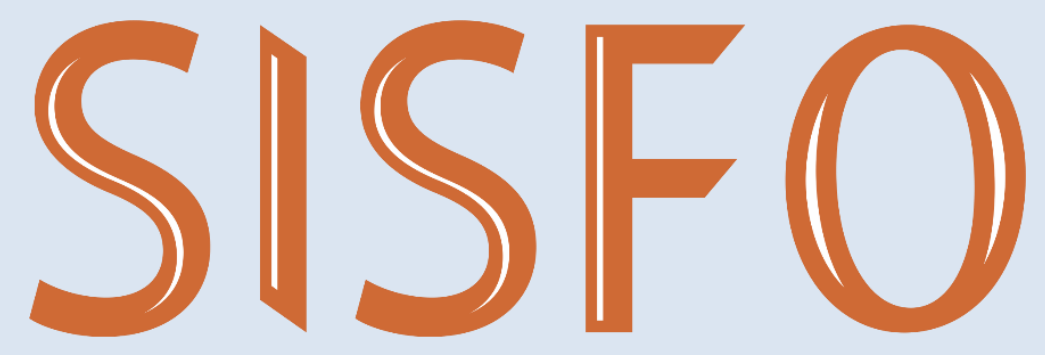

Inspirasi Profesional Sistem Informasi

\section{People}

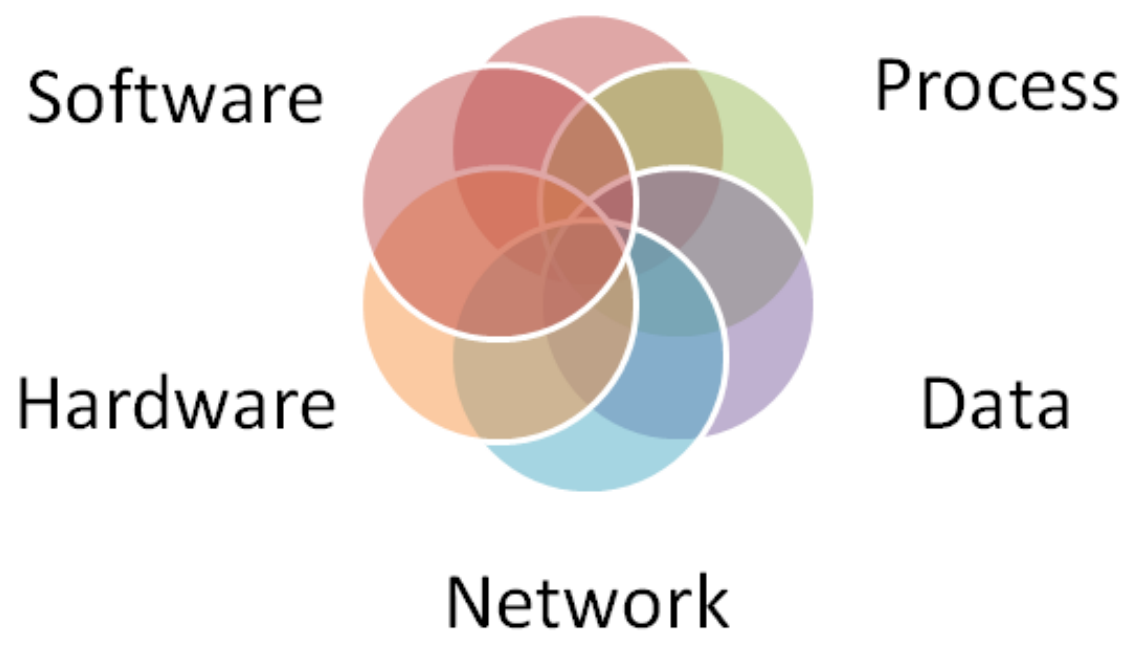


OAJIS

Journal of

Information

Systems

is.its.ac.id/pubs/oajis/

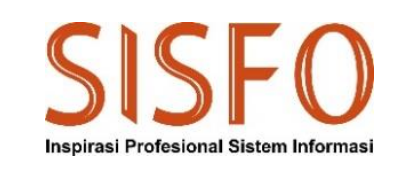

Jurnal Sisfo Vol. 09 No. 01 (2019) i-ii

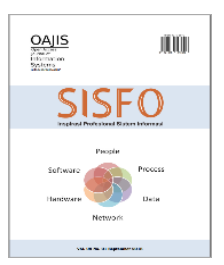

\section{Pimpinan Redaksi}

Faizal Mahananto

\section{Dewan Redaksi}

Eko Wahyu Tyas Darmaningrat

Amna Shifia Nisafani

Arif Wibisono

Rully Agus Hendrawan

\section{Tata Pelaksana Usaha}

Achmad Syaiful Susanto

Rini Ekowati

\section{Sekretariat}

Departemen Sistem Informasi - Fakultas Teknologi Informasi dan Komunikasi

Institut Teknologi Sepuluh Nopember (ITS) - Surabaya

Telp. 031-5999944 Fax. 031-5964965

Email: editor@jurnalsisfo.org

Website: http://jurnalsisfo.org

Jurnal SISFO juga dipublikasikan di Open Access Journal of Information Systems (OAJIS)

Website: http://is.its.ac.id/pubs/oajis/index.php 
OAJIS Journal of Information

Systems

is.its.ac.id/pubs/oajis/

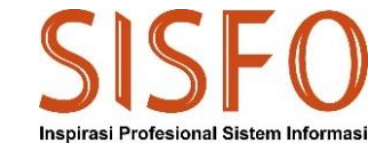

Jurnal Sisfo Vol. 09 No. 01 (2019) i-ii

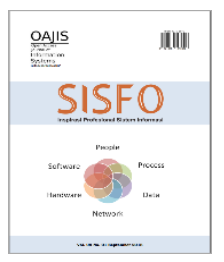

\section{Mitra Bestari}

A'ang Subiyakto, S.Kom., M.Kom., Ph.D. (UIN Syarif Hidayatullah Jakarta)

Alvin Sahroni, S.T., M.Eng., Ph.D. (Universitas Islam Indonesia)

Leon Andretti Abdillah, S.Kom., M.M. (Universitas Bina Darma)

Nur Aini Rakhmawati, S.Kom., M.Sc.Eng., Ph.D. (Institut Teknologi Sepuluh Nopember)

Renny Sari Dewi, S.Kom., M.Kom. (Universitas Internasional Semen Indonesia)

Reny Nadlifatin, S.Kom., M.BA., Ph.D. (Institut Teknologi Sepuluh Nopember)

Retno Aulia Vinarti, S.Kom., M.Kom., Ph.D. (Institut Teknologi Sepuluh Nopember)

Rradityo Prasetianto Wibowo, S.Kom., M.Kom. (Institut Teknologi Sepuluh Nopember)

Satria Fadil Persada, S.Kom., M.BA., Ph.D. (Institut Teknologi Sepuluh Nopember)

Sholiq, S.T., M.Kom. (Institut Teknologi Sepuluh Nopember)

Yogantara Setya Dharmawan, S.Kom., MBusProcessMgt (Universitas Internasional Semen Indonesia) 


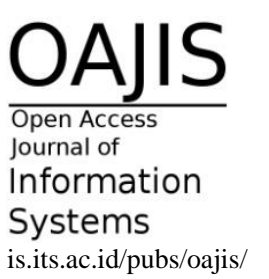

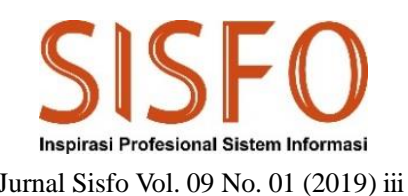

Jurnal Sisfo Vol. 09 No. 01 (2019) iii

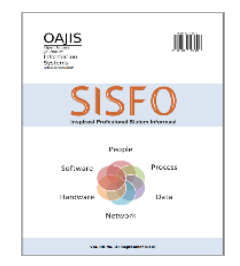

\section{Daftar Isi}

Perencanaan Strategi SI/TI Menggunakan Metode Ward and Peppard di BARENLITBANGDA Kabupaten Semarang

Dedy, Prihanto Ngesti Basuki, Hanna Prillysca Chernovita

Penggunaan Algoritma C4.5 untuk Rekomendasi Peminjaman Uang pada Koperasi Sejahtera Mandiri

Muhammad Imam Tegar, Wachyu Hari Haji.....

Analysis of Purchase Intention using Mobile Shopping Application for Generation X and Y in Indonesia

Mudjahidin, Andre Parvian Aristio, Al Lilah Nur Hasanah.

Analisis Struktur Service Desk di Perguruan Tinggi (Studi Kasus: Institut Teknologi Sepuluh Nopember Surabaya)

Anisah Herdiyanti, Mona Syahmi, Tony Dwi Susanto

Analisis Intensi Perilaku Untuk Mengadopsi dan Merekomendasikan Aplikasi Mobile Payment dengan Metode Structural Equation Modelling

Andre Parvian Aristio, Mudjahidin, Nasywa Ibtisamah. 51 
Halaman ini sengaja dikosongkan 
OAJIS

Open Acces

Journal of

Information

Systems

is.its.ac.id/pubs/oajis/

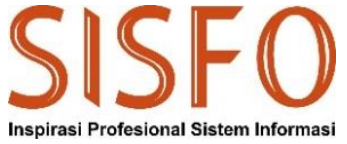

Jurnal SISFO Vol.09 No.01 (2019) 1-14

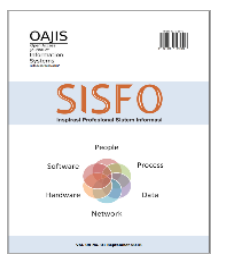

\title{
Perencanaan Strategi SI/TI Menggunakan Metode Ward and Peppard di BARENLITBANGDA Kabupaten Semarang
}

\author{
Dedy*, Prihanto Ngesti Basuki, Hanna Prillysca Chernovita \\ Departemen Sistem Informasi, Universitas Kristen Satya Wacana, Salatiga 50711, Indonesia
}

\begin{abstract}
BARENLITBANGDA of Semarang regency is one of non-profit organizations engaged in planning, research and development field in Semarang regency. The existence of information system and information technology (IS/IT) is a tool to successfully achieve vision and mission of government in the digital era. However, not all business processes in BARENLITBANGDA were supported by the information system and information technology, therefore the performance process has not been run effectively and efficiently. The purpose of this research is to maximize IS/IT management and to look after potential matters/systems that have not been fully utilized to improve organization quality. This research implements Ward and Peppard method which consist of SWOT, Value Chain, Critical Success Factors, and Mc Farlan's Strategic Grid analysis. The result shows the information system requirement, information system strategic solution and recommendations in the main activities and supporting activities that have been defined into strategic planning for future four-year implementation plannings.
\end{abstract}

Keywords: Information System, Strategic Planning, Ward and Peppard

\begin{abstract}
Abstrak
BARENLITBANGDA Kabupaten Semarang merupakan salah satu organisasi non-profit yang bergerak di bidang Perencanaan, Penelitian dan Pengembangan Daerah Kabupaten Semarang. Adanya sistem informasi dan teknologi informasi (SI/TI) merupakan alat untuk mencapai kesuksesan visi misi pemerintahan era digital. Namun, saat ini belum semua proses bisnis BARENLITBANGDA didukung oleh penggunaan SI/TI, sehingga kinerjanya belum berjalan dengan efektif dan efisien. Dengan memaksimalkan pengelolaan manajemen SI/TI dan melihat potensi yang belum sepenuhnya dimanfaatkan diharapkan dapat meningkatkan nilai kualitas organisasi. Penelitian ini menggunakan metode Ward and Peppard yang terdiri dari analisis SWOT, Value Chain, Critical Succes Factors, dan Mc Farlan's Strategic Grid yang akan menghasilkan gambaran kebutuhan sistem informasi, solusi dan rekomendasi strategi sistem informasi dalam aktivitas utama dan aktivitas pendukung yang selanjutnya dapat dirumuskan perencanaan strategi untuk rencana implementasi yang akan dilakukan dalam 4 (empat) tahun yang akan datang.
\end{abstract}

Kata kunci: Perencanaan Strategis, Sistem Informasi, Ward and Peppard

(C) 2019 Jurnal SISFO.

Histori Artikel: Disubmit 08-07-2019; Direvisi 16-08-2019; Diterima 23-08-2019; Tersedia online 05-09-2019

${ }^{*}$ Corresponding Author

Email address: 682015061@ student.uksw.edu (Dedy)

https://doi.org/10.24089/j.sisfo.2019.09.001 


\section{Pendahuluan}

Perkembangan sistem informasi dan teknologi informasi (SI/TI) yang sangat cepat sekarang ini menyebabkan perubahan-perubahan peran yang penting dalam proses bisnis sebuah organisasi serta memberikan peningkatan efisiensi dan efektivitas kinerja organisasi. Karena perannya yang strategis, teknologi informasi juga dapat dijadikan sebagai senjata bagi sebuah organisasi untuk memperoleh keunggulan kompetitif dalam memasuki era revolusi industri [1]. Oleh karena itu, strategi SI/TI sering digunakan dalam instansi pemerintah untuk menunjang pengembangan kualitas SI/TI dan meningkatkan nilai dari organisasi untuk terwujudnya visi misi dan pemerintahan era E-Government yang saat ini menjadi program pemerintah.

BARENLITBANGDA Kabupaten Semarang merupakan salah satu organisasi non-profit instansi pemerintahan yang bergerak pada bidang Perencanaan, Penelitian dan Pengembangan Daerah Kabupaten Semarang yang terletak pada Jalan Gatot Subroto Nomor 20 Ungaran. Badan Perencanaan Pembangunan merupakan salah satu SKPD yang ada di Kabupaten Semarang yang mempunyai tugas pokok melaksanakan penyusunan dan pelaksanaan kebijakan daerah di bidang perencanaan pembangunan daerah. BARENLITNBANGDA Kabupaten Semarang ini mempunyai 5 bidang yaitu bidang sekretariat, bidang perencanaan pemerintah dan sosial, perencanaan ekonomi dan prasarana wilayah, perencanaan pembangunan daerah dan bidang penelitian dan pengembangan.

Perencanaan program kerja yang strategis merupakan suatu cara menerapkan sumber daya yang tersedia dan produk-produk atau jasa yang akan disediakan dengan seoptimal mungkin. Saat ini organisasi sektor publik tengah menghadapi berbagai tantangan dan tuntutan untuk bekerja lebih efisien [2]. Pemanfaatan seluruh sumber daya yang dimiliki instansi secara optimal perlu dilakukan untuk menyelesaikan permasalahan secara cepat dan tepat. Program pemerintahan yang baik (goodgovernance) dan peningkatan layanan publik yang efektif dan efisien memerlukan adanya kebijakan dan strategi pengembangan e-government [3]. Selain itu, sumber daya informasi yang dimiliki suatu instansi dapat mendukung aktivitas dan peningkatan kinerja yang berkualitas, akan tetapi sering terjadi permasalahan saat manajeman informasi seperti adanya pemberian informasi salah atau tidak tepat sehingga instansi harus menanggung risiko yang timbul oleh kesalahan informasi.

Kegiatan BARENLITBANGDA Kabupaten Semarang saat ini masih banyak yang belum menggunakan SI/TI untuk menunjang aktivitas yang dilakukan organisasi agar lebih efisien dan efektif. Pembangunan SI/TI pastinya penting untuk pemeliharaan data dan pengarsipan data. Dokumen berupa laporan, buku, surat, dan data-data lainya sangat penting bagi sebuah instansi. Pengelolaan data yang kurang efektif dan kurang baik dapat mengakibatkan dampak buruk pada kinerja instansi atau pihak-pihak yang terkait. Dengan minimnya SI/TI untuk mengelola proses kinerja maka akan berpengaruh pada proses kinerja yang kurang efektif dan efisien, permasalahaan tersebut juga akan berpengaruh pada kualitas pengambilan keputusan. Melihat pentingnya pemanfaatan SI/TI untuk meminimalkan risiko-risiko yang dimiliki oleh organisasi, maka dibutuhkan perencanaan strategi yang sesuai dan dukungan dari pihak-pihak terkait agar dapat mengoptimalkan SI/TI pada BARENLITBANGDA Kabupaten Semarang. Penelitian ini bertujuan untuk menyusun rumusan perencanaan strategi SI/TI pada BARENLITBANGDA Kabupaten Semarang dengan menggunakan metode yang dikembangkan oleh John Ward dan Joe Peppard (Ward and Peppard) [4]. Adapun Tools yang digunakan dalam metode Ward and Peppard terdiri dari analisis SWOT, analisis Value Chain, metode Critical Succes Factors, dan Mc Farlan's Strategy Grid. Hasil dari penelitian ini berupa perencanaan strategis sistem informasi dan teknologi informasi yang diharapkan dapat memberikan masukan bagi tercapainya visi misi pemerintahan berbasis teknologi (e-government) pada BARENLITBANGDA Kabupaten Semarang. 


\section{Tinjauan Pustaka/Penelitian Sebelumnya}

Sistem informasi (SI) adalah suatu sistem buatan manusia yang secara umum terdiri atas sekumpulan komponen berbasis komputer dan manual yang dibuat untuk menghimpun, menyimpan, dan mengelola data serta menyediakan informasi luaran kepada pemakai [5]. Sistem informasi melayani tingkatan yang ada dalam organisasi yakni tingkat strategi, manajemen, pengetahuan dan operasional [6].

Pengertian teknologi informasi (TI) menurut Ward dan Peppard [4] menunjuk pada spesifikasi mengenai teknologi, khususnya hardware, software dan jaringan telekomunikasi yang memfasilitasi dan mendukung proses pengumpulan, pengolahan, penyimpanan, penyebaran dan pertukaran informasi. Menurut O'Brien (dalam Wandikbo dan Sitokdana [7]), teknologi informasi meliputi konsep-konsep utama, pengembangan dan berbagai isu manajemen teknologi informasi yaitu hardware, software, jaringan, manajemen data dan banyak teknologi berbasis internet. Jadi teknologi informasi merupakan suatu konsep utama yang berhubungan dengan teknologi yang nantinya akan mendukung suatu sistem [8].

Perencanaan strategis sistem informasi merupakan proses identifikasi portofolio aplikasi SI berbasis komputer yang mendukung suatu organisasi dalam pelaksanaan rencana bisnis dan merealisasikan tujuan bisnisnya [1]. Perencanaan strategis SI/TI mempelajari pengaruh SI/TI terhadap kinerja bisnis dan kontribusi bagi organisasi dalam memilih langkah-langkah strategis. Selain itu, perencanaan strategis SI/TI juga menjelaskan berbagai alat, teknik, dan kerangka kerja bagi manajemen untuk menyelaraskan strategi SI/TI dengan strategi bisnis, bahkan mencari kesempatan baru melalui penerapan teknologi yang inovatif [4].

Beberapa karakteristik dari perencanaan strategis SI/TI antara lain adalah adanya misi utama, yaitu keunggulan strategis atau kompetitif dan kaitannya dengan strategi bisnis; adanya arahan dari eksekutif atau manajemen senior dan pengguna; serta pendekatan utama berupa inovasi pengguna dan kombinasi pengembangan bottom up dan analisa top down [9]. Perencanaan strategis SI/TI yang baik akan menghasilkan portfolio sistem informasi dan infrastruktur yang saling terintegrasi di semua level organisasi dan memberikan kontribusi yang penting dalam membangun dan meningkatkan kinerja organisas [7].

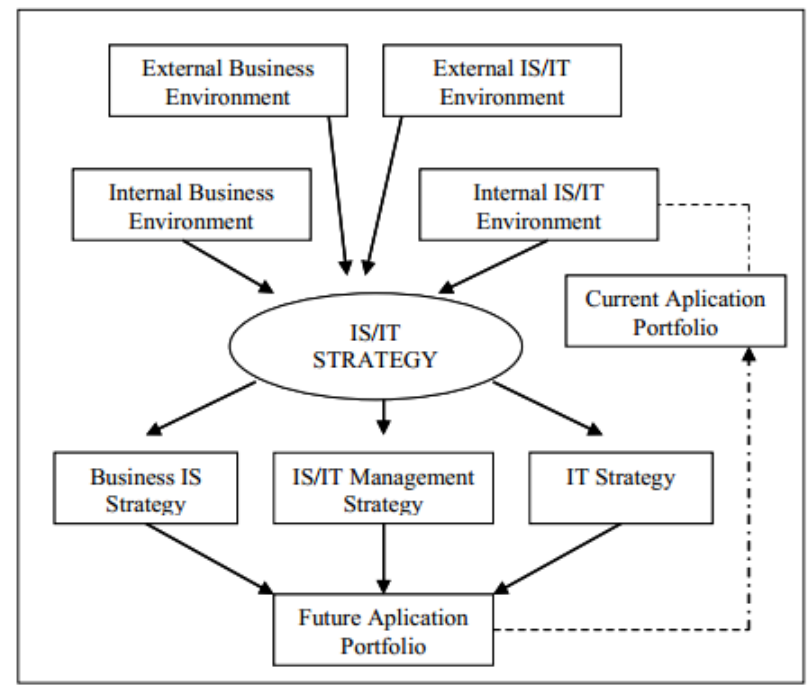

Gambar 1. Model strategis SI/TI Ward and Peppard [1]

Pendekatan metodologi versi Ward and Peppard ini dimulai dari kondisi investasi SI/TI dimasa lalu yang kurang bermanfaat bagi tujuan bisnis organisasi dan menangkap peluang bisnis, serta fenomena meningkatkan keunggulan kompetitif suatu organisasi karena mampu memanfaatkan SI/TI dengan maksimal. Kurang bermanfaatnya investasi SI/TI bagi organisasi disebabkan karena perencanaan strategis 
SI/TI yang lebih fokus ke teknologi, bukan berdasarkan kebutuhan bisnis [9]. Metodologi versi ini terdiri dari tahapan masukan dan tahapan luaran yang disajikan dalam skema perencanaan strategis SI/TI Ward dan Peppard yang terlihat pada Gambar 1 .

Metode Ward and Peppard terdiri dari tahapan masukan dan tahapan luaran. Tahapan masukan terdiri dari 4 macam analisis, antara lain [7]:

1) Analisis lingkungan bisnis internal, yang mencakup aspek-aspek strategi bisnis saat ini, sasaran, sumber daya, proses, serta budaya nilai-nilai bisnis organisasi.

2) Analisis lingkungan bisnis eksternal, yang mencakup aspek-aspek ekonomi, industri, dan iklim bersaing perusahaan.

3) Analisis lingkungan SI/TI internal, yang mencakup kondisi SI/TI organisasi dari perspektif bisnis saat ini, bagaimana kematangannya (maturity), bagaimana kontribusi terhadap bisnis, keterampilan sumber daya manusia, sumber daya dan infrastruktur teknologi, termasuk juga bagaimana portofolio dari SI/TI yang ada saat ini.

4) Analisis lingkungan SI/TI eksternal, yang mencakup tren teknologi dan peluang pemanfaatannya, serta penggunaan SI/TI oleh kompetitor, pelanggan dan pemasok.

Sedangkan tahapan keluaran merupakan bagian yang dilakukan untuk menghasilkan suatu dokumen perencanaan strategis SI/TI yang isinya terdiri dari [1]:

1) Strategi SI bisnis, yang mencakup bagaimana setiap unit atau fungsi bisnis akan memanfaatkan SI/TI untuk mencapai sasaran bisnisnya, portofolio aplikasi dan gambaran arsitektur informasi.

2) Strategi TI, yang mencakup kebijakan dan strategi bagi pengelolaan teknologi dan sumber daya manusia SI/TI.

3) Strategi Manajemen SI/TI, yang mencakup elemen-elemen umum yang diterapkan melalui organisasi, untuk memastikan konsistensi penerapan kebijakan SI/TI yang dibutuhkan.

Penelitian pertama yang dilakukan oleh Wedhasmara [10] juga menggunakan metode Ward and Peppard. Hasil dari penelitian ini adalah menyelaraskan antar strategi SI/TI untuk mendapatkan nilai tambah dari suatu organisasi dari segi keunggulan kompetitif yang nanti hasil dari perencanaan strategi SI/TI menjawab permasalahan pemanfaatan SI/TI suatu organisasi, dan hasil identifikasi berupa portofolio aplikasi SI/TI. Sedangkan penelitian kedua yang dilakukan oleh Kurniawati [11] menggunakan metode Ward and Peppard dengan menggunakan teknik analisis Five Forces Competitive, analisis SWOT, analisis Value Chain dan Mc Farlan's Strategi Grid. Hasil yang didapat dari penelitian ini adalah dokumen portofolio aplikasi perencanaan strategis sistem informasi yang mencakup strategi bisnis, strategi sistem informasi dan strategi teknologi informasi yang disesuaikan dengan kebutuhan Dinas Perhubungan Kabupaten Garut.

Penelitian ketiga yang dilakukan oleh Thomas dan Tambotoh [1] menggunakan metode John Ward dan Joe Peppard, dengan menggunakan metode analisis PEST, analisis SWOT, Value Chain Activity, dan analisis CSF dengan Balanced Scorecard. Hasil yang diperoleh berupa suatu kerangka kerja perencanaan strategis SI/TI yang terintegrasi sehingga memudahkan manajemen mengelola sumber daya yang tergambar dalam portofolio aplikasi, menghasilkan informasi yang dibutuhkan dan dapat digunakan secara bersama oleh semua pihak. Sedangkan penelitian keempat yang dilakukan oleh Hirawan dan Hadiana [12] menggunakan tools analisa PEST dan CobiT 4.1. Hasil dari penelitian ini adalah Kebutuhan sistem informasi di setiap satuan perangkat kerja daerah (SKPD) memang berbeda sesuai dengan tugas pokok dan fungsinya, hanya saja dalam pengelolaan proses bisnis internal di setiap SKPD perlu adanya peran sistem informasi yang terintegrasi dan dapat mengelola diantaranya data kepegawaian, pengelolaan keuangan daerah, serta pengelolaan asset. Diharapkan dengan adanya ketiga sistem informasi tersebut kedepannya dapat memudahkan dalam proses pengawasan kinerja setiap SKPD [12]. 


\section{Metodologi}

Pengumpulan data dalam penelitian ini menggunakan metode kualitatif, karena melalui pendekatan yang bersifat deskriptif ini dapat menganalisa keadaan lingkungan dengan subjektif dalam fakta-fakta di lingkungan. Dalam penelitian ini mempunyai tahapan seperti Gambar 2 yang nantinya dapat diambil kesimpulan, yaitu:

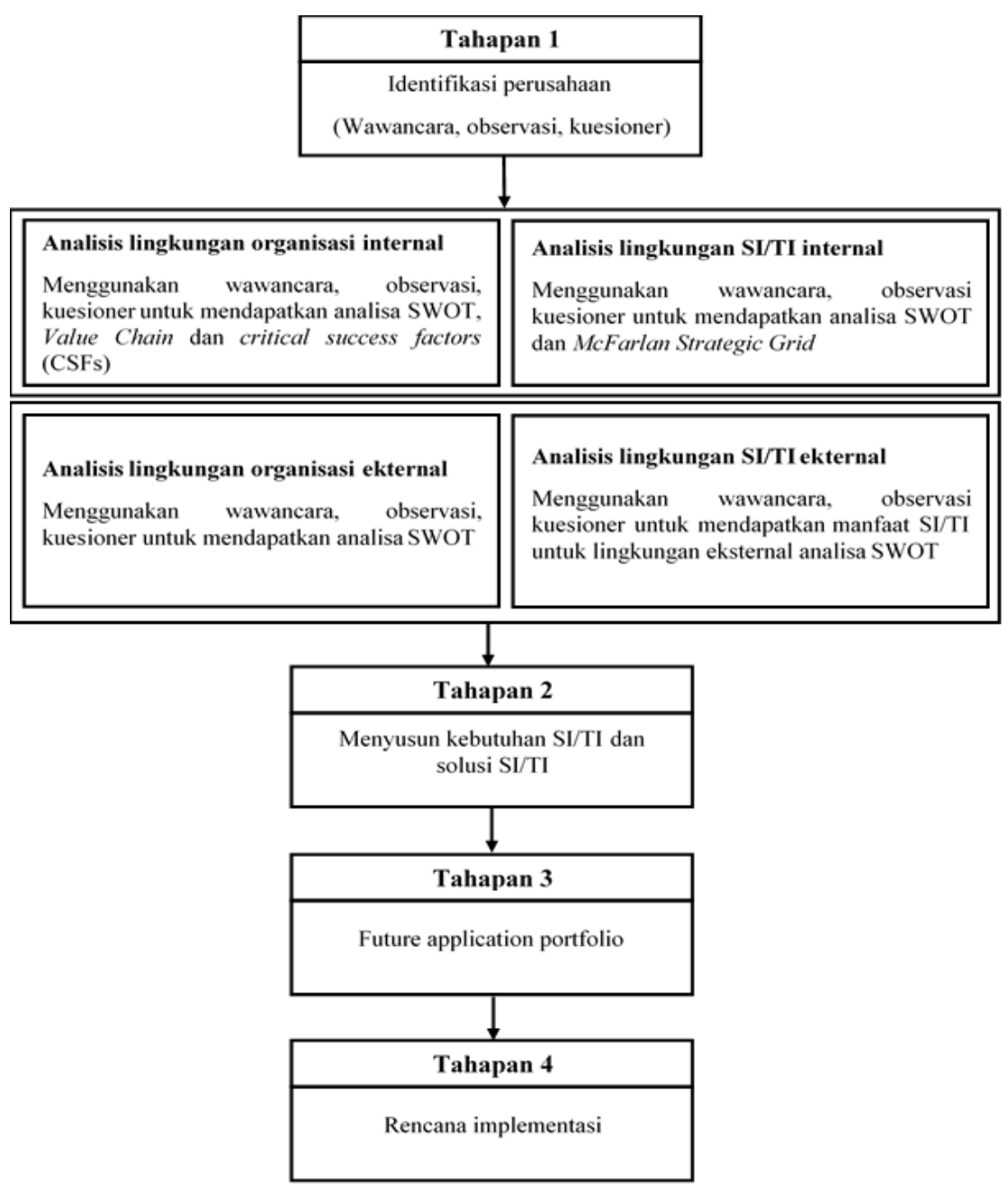

Gambar 2 Tahapan Penelitian

Kegiatan observasi dilakukan pada salah satu instansi pemerintah BARENLITBANGDA Kabupaten Semarang selama dua bulan. Pengamatan ini bertujuan untuk mengetahui identitas organisasi (profil, tujuan, dan visi misi organisasi), serta proses bisnis dan kondisi SI/TI yang ada di organisasi tersebut. Metode wawancara digunakan untuk memahami keadaan proses kerja lebih mendalam dan penerapan SI/TI yang sudah dilakukan pada organisasi, wawancara dilakukan dengan fungsional perencana pertama yang dibawah perintah Kepala BARENLITBANGDA dan staf TI BARENLITBANGDA. Selanjutnya, metode kuesioner menggunakan Ward and Peppard untuk memperoleh data yang akan diisi oleh responden dari 5 Bidang yang berurusan dengan SI/TI organisasi. Metode pengumpulan sampel yang digunakan adalah purposive sampling, yaitu teknik pengambilan sampel dengan menentukan kriteria-kriteria tertentu [13]. Teknik sampel mengambil 30\% dari jumlah total 40 responden dan setiap responden mewakili kesamaan karakter 
dalam setiap bidang. Teknik sampling untuk mereduksi jumlah populasi anggota menjadi anggota sampel yang mewakili populasinya (representatif) [14].

Tahapan 1 menggambarkan tentang bagaimana proses mengumpulkan dan mengidentifikasi informasi tentang profil, visi, misi dan tujuan organisai dengan cara observasi, wawancara dan kuesioner untuk mendapatkan informasi dan data yang valid di BARENLITBANGDA Kabupaten Semarang. Tahapan 1 juga tahapan untuk memahami lingkungan organisasi internal, lingkungan organisasi eksternal dan pemanfaatan SI/TI yang diterapkan organisasi saat ini. Output tahapan ini adalah mengetahui bagaimana keadaan kekuatan, kelemahan, ancaman dan peluang dari organisasi yang selanjutnya dapat diolah untuk melakukan analisa SWOT untuk mengetahui kekuatan, kelemahan, ancaman dan peluang. Selanjutnya dilakukan pemetaan strategi untuk memaksimalkan kekuatan dan peluang organisasi serta meminimalkan kelemahan dan ancaman. Analisis Value Chain digunakan untuk menunjukan aktivitas utama dan aktivitas pendukung, sedangkan analisis CSFs dilakukan untuk memahami tentang rekomendasi organisasi, dan analisis McFarlan Strategic Grid untuk memerakan apa yang akan dilakukan organisasi di masa yang akan datang untuk meningkatkan kualitas dan pencapaian visi misi organisasi.

Tahapan 2 adalah untuk menganalisa kebutuhan-kebutuhan pada organisasi dan nantinya memberikan rekomendasi tentang kebutuhan SI/TI dan solusi SI/TI organisasi dengan mengunakan analisa CSFs. Tahapan ini sebagai tahap untuk melihat tentang bagaimana mengelola usulan dari peluang-peluang dan mengelola risiko tersebut untuk mendapatkan strategi SI/TI pada organisasi.

Pada tahapan ketiga, berdasarkan analisis dari tahapan sebelumnya maka dapat diperoleh perumusan perencanaan strategi untuk pemetaan priortitas kebutuhan SI/TI organisasi yang akan dilakukan dimasa yang akan datang dengan menggunakan analisa McFarlan Strategi Grid.

Selanjutnya pada tahapan keempat, berdasarkan hasil portofolio aplikasi dengan analisa McFarlan Strategi Grid maka selanjutnya dapat dirumuskan perencanaan strategi untuk rencana implementasi yang akan dilakukan dalam 4 (empat) tahun yang akan datang.

\section{Hasil dan Pembahasan}

\subsection{Analisis SWOT}

Tahap awal analisa dilakukan dengan menggunakan tools Analisis Strengths, Weaknesses, Opportunities, Threats (SWOT), yaitu identifikasi lingkungan secara sistematis untuk merumuskan strategi perusahaan [15]. Tujuan dari analisa ini untuk mengetahui kondisi lingkungan internal dan eksternal pada BARENLITBANGDA Kabupaten Semarang. Dari hasil analisa tersebut maka akan diperoleh gambaran untuk menyusun rencana strategi organisasi, sehingga BARENLITBANGDA Kabupaten Semarang dapat memanfaatkan kekuatan dan peluang untuk meminimalkan kelemahan dan ancaman yang dimiliki organisasi yang nantinya akan menghasilkan strategi SI/TI dalam pencapaian visi misi organisasi. Tabel 1 menunjukkan hasil analisis SWOT BARENLITBANGDA Kabupaten Semarang.

Dari hasil analisis SWOT pada Tabel 1 yang menunjukkan kondisi lingkungan internal dan eksternal organisasi saat ini, kemudian digunakan untuk merumuskan dan menentukan solusi dari hasil diagram matriks SWOT BARENLITBANGDA seperti pada Tabel 2. 
Tabel 1. Tabel analisa SWOT BARENLITBANGDA Kabupaten Semarang

S (Strengths) faktor kekuatan internal

1) Staf telah memahami Visi Misi dan tugas-tugas Jabatannya.

2) Peran Kepala BARENLITBANGDA yang sangat penting dalam penyusunan perencanaan pembangunan dan pencapaian visi misi.

3) Penyusunan materi, RPJP, RPJM, RKPD Renstra/Renja SKPD dilakukan sesuai waktu yang ditetapkan.

4) Melakukan monitoring dan evaluasi terhadap kegiatan yang sudah berjalan.

5) Memanfaatkan dokumen lama untuk penyusunan perencanaan yang baru.

6) Adanya komitmen untuk mewujudkan pemerintahan egovernment dan informasi layanan Publik yang akurat dan berkualitas,

7) Memiliki ruang backup data untuk setiap aplikasi yang digunakan.

8) Pembuatan aplikasi BARENLITBANGDA dibuat dan dikembangkan oleh developer.

9) Sudah terdapat aplikasi yang dikembangakn oleh BARENLITBANGDA untuk melakukan monitoring, evaluasi, anggaran (SIMPEDA), SIMMISKIN (data kemiskinan) dan web BARENLITBANGDA.

10) Melakukan koordinasi dan evaluasi antar bidang.
$\mathrm{W}$ (Weaknesses) faktor kelemahan internal

1) Belum tersedia SDM yang Berkualitas dan Professional.

2) pendistribusian pekerjaan masih belum merata.

3) belum ada sistem untuk Aset-aset, pengarsipan, surat menyurat, disposisi, fasilitas, perpustakaan pribadi.

4) Tidak adanya penghargaan atau reward kepada SKPD atau staf yang mencapai target (berdasarkan evaluasi kinerja).

5) Masih belum ada kemudahaan dalam akses pencarian data arsip dan buku perencanaan pembangunan.

6) Belum maksimalnya koordinasi dan sinkronisasi informasi antar bidang.

7) Jaringan internet yang belum stabil.

8) Belum mempunyai bidang TI.

9) Belum terdapat training khusus untuk penggunaan aplikasi untuk pegawai baru maupun lama.
$\mathrm{O}$ (Opportunities) faktor peluang eksternal

1) Tersedianya lulusan dengan SDM yang berkualitas.

2) Meningkatakan kualitas SDM yang sudah ada.

3) Mengintegrasikan sistem yang sudah ada dengan pemda dan pihak ke tiga.

4) masyarakat bisa memasukan informasi ke pemda terkait masalah-masalah yang ada pada lapangan.

5) memenuhi kebutuhan setiap perubahan dan tuntutan yang ada di Masyarakat.

6) koordinasi dan evaluasi kegiatan dengan instansi pemerintahan agar kegiatan berjalan dengan lancar.

7) Bekerja sama dengan pihak luar (industri, masyarakat, wirausaha dll) dalam kegiatan pembangunan daerah Kabupaten Semarang.

8) Koordinasi perubahan peraturan dari pemerintah pusat dengan cepat antar pemda.

9) Ketersedianya data-data pendukung untuk perencanaan sudah sangat baik dan optimal.
$\mathrm{T}$ (Threats) faktor ancaman eksternal

1) Peluang Cracking untuk membobol atau iseng pada sistem yang di BARENLITBANGDA

2) Server down atau rusak dalam proses kinerjanya

3) Pengelolaan aplikasi berpindah ke pemda lain.

4) Bencana alam yang mungkin bisa terjadi seperti (kebakaran, gempa bumi dll)

5) Peraturan pemerintah yang berubah-ubah setiap tahun.

6) Pencarian data dan informasi antar instansi pemerintahan Kabupaten Semarang yang lambat dan tidak sinkron.

7) Informasi pelayanan publik yang tidak sesuai.

Tabel 2 menjelaskan tentang solusi strategi untuk menghadapi kondisi lingkungan BARENLITBANGDA. Analisis strategi S-O dilakukan untuk mendapatkan solusi yang memaksimalkan kekuatan organisasi dengan memanfaatkan peluang, sedangkan strategi S-T dilakukan dalam menentukan solusi organisasi yang menggunakan kekuatan untuk mengatasi ancaman. Selanjutnya strategi W-O untuk mendapatkan solusi yang menciptakan strategi dalam meminimalkan kelemahan organisasi untuk memanfaatkan peluang, dan strategi W-T dilakukan untuk menentukan strategi dalam meminimalkan kelemahan dan menghindari ancaman. 
Tabel 2. Tabel analisis SWOT BARENLITBANGDA Kabupaten Semarang

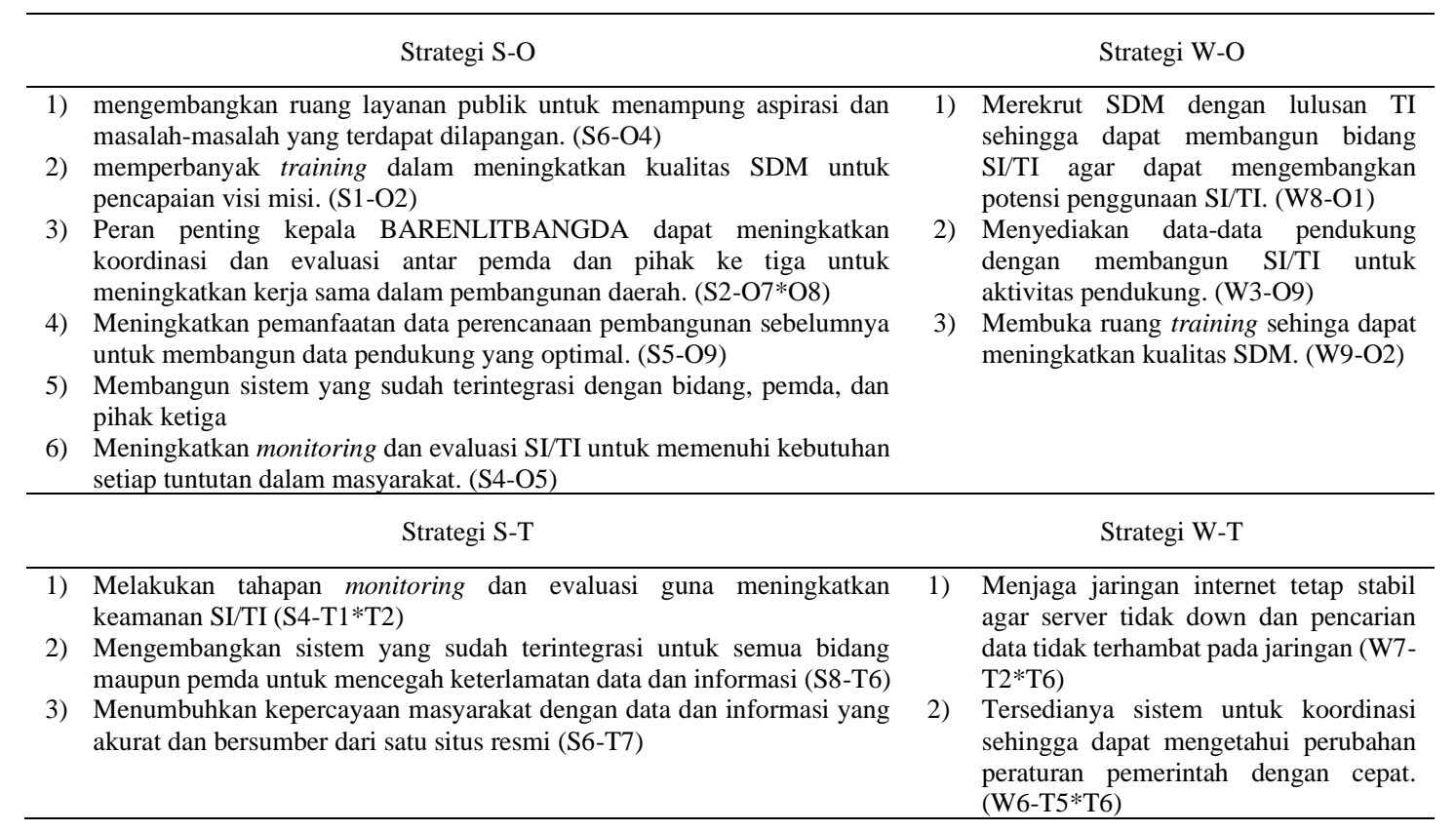

\subsection{Analisa Value Chain}

Analisa value chain dilakukan dengan metode wawancara kepada staf fungsional perencana pertama dan staf IT untuk mengetahui proses organisasi berjalan, observasi dilakukan untuk memahami keadaan lingkungan yang berfokus pada tugas dan proses kerja internal yang dilakukan BARENLITBANGDA Kabupaten Semarang. Analisa ini juga bertujuan untuk mengidentifikasi dan mengelompokkan aktivitasaktivitas yang terjadi di perusahaan ke dalam dua bagian besar yaitu aktivitas utama dan aktivitas pendukung [9]. Gambar 3 berikut menyajikan hasil analisa value chain pada BARENLITBANGDA Kabupaten Semarang.

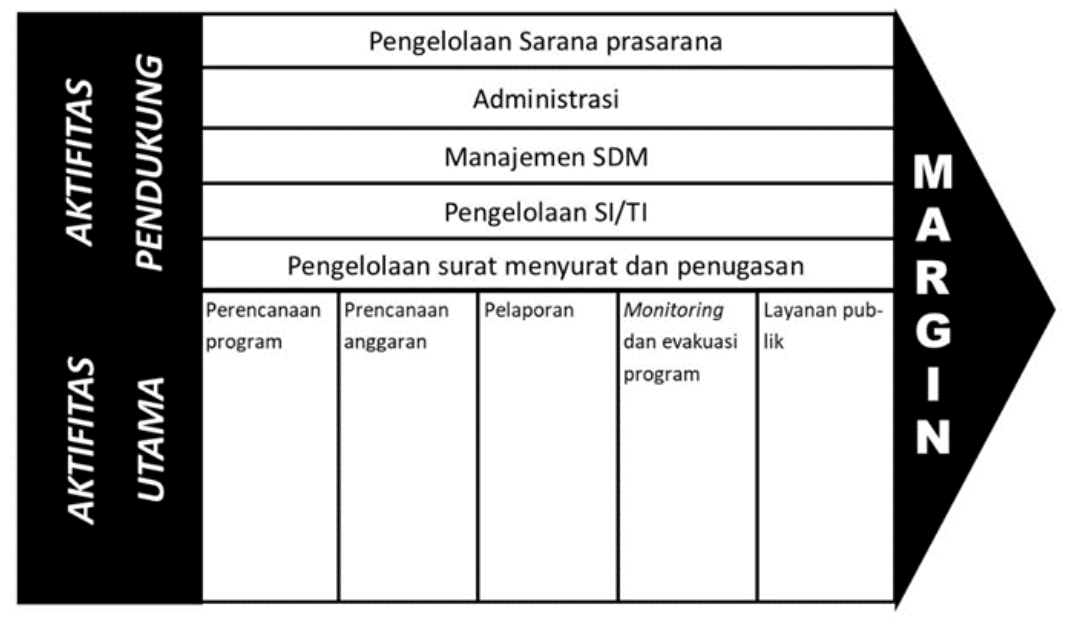

Gambar 3. Diagram value chain BARENLITBANGDA Kabupaten Semarang 
Identifikasi penerapan sistem informasi yang digunakan pada BARENLITBANGDA secara internal dilakukan untuk mengetahui sejauh mana sistem yang dikembangkan oleh organisasi. Adapun daftar sistem informasi yang digunakan dan dikembangkan oleh organisasi saat ini yaitu seperti pada Tabel 3.

Tabel 3. Tabel penerapan SI pada BARENLITBANGDA

\begin{tabular}{clll}
\hline No & \multicolumn{1}{c}{ Nama Sistem } & Pengguna & Jenis Aplikasi \\
\hline 1 & SIMPEDA (monitoring, evaluasi, angaran) & Bidang & Web \\
2 & SIMMISKIN & Admin & Web \\
3 & Web BARENLITBANGDA & Admin & Web \\
4 & SI Absensi & umum & Desktop \\
\hline
\end{tabular}

Tabel 3 menjelaskan penerapan sistem informasi yang sudah dikembangkan oleh organisasi. Dengan aplikasi SIMPEDA organisasi dapat mengawasi, mengevaluasi kegiatan yang sudah berjalan, serta membuat rangkaian kegiatan dan anggaran yang diperlukan oleh organisasi. Aplikasi SIMMISKIN bertujuan untuk mengetahui data kemiskinan masyarakat Kabupaten Semarang. Dengan adanya sistem tersebut maka BARENLITBANGDA dapat mengukur tingkat kemiskinan masyarakat. Web BARENLITBANGDA menjadi website resmi yang dimiliki dan dikelola organisasi yang bertujuan untuk menyediakan berita dan informasi. SI Absensi sebagai alat monitoring absensi pegawai yang bertujuan agar staf menjadi disiplin dalam ketepatan waktu berangkat dan pulang kerja.

\subsection{Analisa Critical Success Factors (CSFs)}

Penelitian ini merupakan suatu kebutuhan dari organisasi dan lingkungannya yang berpengaruh pada keberhasilan atau kegagalan. CSFs dapat ditentukan jika objektif organisasi telah diidentifikasi. Tujuan dari CSFs adalah menginterpretasikan objektif secara lebih jelas untuk menentukan aktivitas yang harus dilakukan dan informasi apa yang dibutuhkan [7]. Analisa Critical Success Factors (CSFs) yang dilakukan pada BARENLITBANGDA bertujuan untuk menggambarkan identifikasi faktor kesuksesan dari organisasi yang fokus untuk melihat kebutuhan SI/TI yang dapat meningkatkan efektivitas dan efisiensi dalam proses kinerja organisasi. Analisa CSFs akan menghasilkan solusi SI/TI yang akan berpengaruh terhadap rencana implementasi SI/TI yang akan dikembangkan BARENLITBANGDA Kabupaten Semarang di masa yang akan datang seperti terlihat pada Tabel 4 .

Tabel 4. Tabel hasil analisis CSFs pada BARENLITBANGDA Kabupaten Semarang

\begin{tabular}{|c|c|c|c|c|}
\hline No & Aktivitas & $\mathrm{CSF}$ & Key Decision & Solusi Aplikasi \\
\hline 1 & Pendukung & $\begin{array}{l}\text { Terwujudnya SDM yang berkualitas } \\
\text { dan mampu saling berkompetisi } \\
\text { didalam memajukan organisasi. }\end{array}$ & $\begin{array}{l}\text { Memberikan fasilitas ruang training untuk staf } \\
\text { lama untuk mempelajari sistem yang terdapat } \\
\text { pada organisasi. }\end{array}$ & $\begin{array}{l}\text { SI Pengelolaan } \\
\text { SDM }\end{array}$ \\
\hline 2 & Utama & $\begin{array}{l}\text { Terciptanya Bidang TI yang dapat } \\
\text { mengembangkan e-government pada } \\
\text { organisasi. }\end{array}$ & $\begin{array}{l}\text { Merekrut SDM TI untuk mengembangkan SI/TI } \\
\text { pada organisasi. }\end{array}$ & $\begin{array}{l}\text { Web } \\
\text { BARENLITBA } \\
\text { NGDA }\end{array}$ \\
\hline 3 & Utama & $\begin{array}{l}\text { Terwujudnya sistem yang sudah } \\
\text { terintergerasi untuk mencapainya visi } \\
\text { misi organisasi. }\end{array}$ & $\begin{array}{l}\text { Membangun sistem yang sudah terintergerasi di } \\
\text { ruang lingkup internal maupun eksternal untuk } \\
\text { tercapainya } e \text {-government. }\end{array}$ & $\begin{array}{l}\text { Sistem yang } \\
\text { terintegrasi }\end{array}$ \\
\hline 4 & Pendukung & $\begin{array}{l}\text { Tersedianya sistem manajemen aset } \\
\text { yang dimiliki organisasi }\end{array}$ & $\begin{array}{l}\text { Membangun sistem untuk mengelola aset yang } \\
\text { dimiliki organisasi, agar aset yang dimiliki selalu } \\
\text { termonitoring umur dan keadaan barang. }\end{array}$ & $\begin{array}{l}\text { SI Manajemen } \\
\text { Aset }\end{array}$ \\
\hline 5 & Pendukung & $\begin{array}{l}\text { Tersedianya pengelolaan buku-buku } \\
\text { perencanaan pembangunan daerah. }\end{array}$ & $\begin{array}{l}\text { Membangun sistem untuk pengelolaan } \\
\text { perpustakaan. }\end{array}$ & SI Perpustakaan \\
\hline
\end{tabular}




\begin{tabular}{|c|c|c|c|c|}
\hline No & Aktivitas & $\mathrm{CSF}$ & Key Decision & Solusi Aplikasi \\
\hline 6 & Pendukung & $\begin{array}{l}\text { Terwujudnya sistem pengelolaan } \\
\text { fasilitas yang terintegrasi. }\end{array}$ & $\begin{array}{l}\text { Membangun sistem pengelolaan fasilitas yang } \\
\text { terintegrasi antar pemda yang dapat } \\
\text { dimanfaatkan untuk kepentingan bersama. }\end{array}$ & SI fasilitas \\
\hline 7 & Pendukung & $\begin{array}{l}\text { Tersedianya pengelolaan data } \\
\text { pengarsipan yang memadai. }\end{array}$ & $\begin{array}{l}\text { Mengembangkan sistem untuk data pengarsipan } \\
\text { untuk ketersediaan data pendukung yang } \\
\text { memadai. }\end{array}$ & SI Pengarsipan \\
\hline 8 & Pendukung & $\begin{array}{l}\text { Terwujudnya surat menyurat dan } \\
\text { penugasan yang terintegrasi. }\end{array}$ & $\begin{array}{l}\text { Membangun e-surat untuk mempermudah } \\
\text { kegiatan surat menyurat dan penugasan berbasis } \\
\text { elektronik yang efektif dan efisien. }\end{array}$ & E-Surat \\
\hline 9 & Pendukung & $\begin{array}{l}\text { Terwujudnya penghargaan kepada } \\
\text { SDM yang berprestasi. }\end{array}$ & $\begin{array}{l}\text { Mengembangkan sistem untuk mengukur } \\
\text { pencapaian prestasi untuk diberikan } \\
\text { penghargaaan, dan dapat dipertimbangkan untuk } \\
\text { rekomendasi kenaik pangkat. }\end{array}$ & SI Prestasi \\
\hline 10 & Pendukung & $\begin{array}{l}\text { Terwujudnya sistem pengelolaan } \\
\text { keuangan yang berkualitas. }\end{array}$ & $\begin{array}{l}\text { Membangun sistem untuk pengelolaan } \\
\text { penggajian dan manajemen keuangan organisasi. }\end{array}$ & SI Akuntansi \\
\hline 11 & Pendukung & $\begin{array}{l}\text { Terciptanya pengelolaan administrasi } \\
\text { yang berkualitas. }\end{array}$ & $\begin{array}{l}\text { Membangun sistem untuk fungsi administrasi } \\
\text { yang berkualitas. }\end{array}$ & SI Administrasi \\
\hline 12 & Utama & $\begin{array}{l}\text { Terwujudnya layanan publik yang } \\
\text { efisien dan berkualitas. }\end{array}$ & $\begin{array}{l}\text { Membangun sistem untuk menampung aspirasi } \\
\text { masyarakat dan masalah yang terdapat di } \\
\text { lapangan dalam bidang pembangunan daerah. }\end{array}$ & $\begin{array}{l}\text { SI Ruang } \\
\text { Publik }\end{array}$ \\
\hline 13 & Utama & $\begin{array}{l}\text { Tersedianya data dan informasi yang } \\
\text { akurat dan berkualitas. }\end{array}$ & $\begin{array}{l}\text { Mengembangkan situs yang menampung data } \\
\text { dan informasi yang terupdate untuk kepentingan } \\
\text { layanan publik. }\end{array}$ & $\begin{array}{l}\text { Web } \\
\text { BARENLITBA } \\
\text { NGDA }\end{array}$ \\
\hline 14 & Pendukung & $\begin{array}{l}\text { Tersedianya sistem untuk monitoring } \\
\text { untuk tamu. }\end{array}$ & Membangun sistem monitoring tamu. & SI Tamu \\
\hline 15 & Pendukung & $\begin{array}{l}\text { Terwujudnya koordinasi yang efektif } \\
\text { dan efisien antar bidang dan pemda. }\end{array}$ & $\begin{array}{l}\text { Membangun sistem ruang koordinasi antar } \\
\text { bidang dan pemda. }\end{array}$ & SI Koordinasi \\
\hline 16 & Utama & $\begin{array}{l}\text { Terwujudnya ruang koordinasi antar } \\
\text { pemda yang berkualitas dengan sumber } \\
\text { data dan inforamasi yang akurat. }\end{array}$ & $\begin{array}{l}\text { Membangun ruang koordinasi antar pemda untuk } \\
\text { proses kinerja dalam klasifikasi sebuah data. }\end{array}$ & SI Data \\
\hline 17 & Utama & $\begin{array}{l}\text { Terwujudnya musyawarah perencanaan } \\
\text { pembangunan daerah yang efektif dan } \\
\text { efisien. }\end{array}$ & $\begin{array}{l}\text { Membangun sistem musyawarah perencanaan } \\
\text { daerah yang lebih efektif dan efisien. }\end{array}$ & SI Musrenbang \\
\hline 18 & Pendukung & $\begin{array}{l}\text { Tercapainya ikatan erat dengan pihak } \\
\text { untuk berkerja sama membangun } \\
\text { daerah. }\end{array}$ & $\begin{array}{l}\text { Membangun sistem untuk kerja sama dengan } \\
\text { pihak ketiga yang efektif dan efisien dalam } \\
\text { rencana pembangunan daerah. }\end{array}$ & SI Kerja Sama \\
\hline 19 & Utama & $\begin{array}{l}\text { Tercapainya rencana yang matang } \\
\text { untuk kegiatan jangka panjang dan } \\
\text { pendek. }\end{array}$ & $\begin{array}{l}\text { Membangun sistem untuk mempermudah } \\
\text { kegiatan dalam membuat rencana jangka panjang } \\
\text { dan pendek. }\end{array}$ & SI Planning \\
\hline 20 & Utama & $\begin{array}{l}\text { Tercapainya pengelolaan evaluasi } \\
\text { kegiatan yang sudah berjalan dan } \\
\text { membuat rangkaian kegiatan dan } \\
\text { anggaran yang diperlukan oleh } \\
\text { organisasi }\end{array}$ & $\begin{array}{l}\text { Mengintergerasikan sistem SIMPEDA agar lebih } \\
\text { optimal dalam menjalankan kegiatan organisasi. }\end{array}$ & SIMPEDA \\
\hline
\end{tabular}

\subsection{McFarlan Strategic Grid}

Strategi solusi SI/TI seperti pada Tabel 4 tersebut akan dipetakan sesuai fungsinya masing-masing menggunakan matriks McFarlan Strategic Grid untuk mengetahui prioritas aplikasi yang akan diterapkan pada BARENLITBANGDA di masa mendatang. Portofolio McFarlan Strategic Grid digunakan untuk memetakan aplikasi sistem informasi berdasarkan kontribusinya terhadap organisasi. Adapun daftar aplikasi 
SI pada BARENLITBANGDA yang dipetakan berdasarkan fungsi aplikasi menggunakan McFarlan Strategic Grid seperti pada Tabel 5.

Tabel 5. Tabel pemetaan fungsi SI berdasarkan McFarlan Grid Portofolio

\begin{tabular}{cll}
\hline Strategic & \multicolumn{1}{c}{ High Potential } \\
\hline- & - SIMMISKIN & \\
& - Web BARENLITBANGDA \\
\hline Key Operational & Support \\
\hline SIMPEDA (monitoring, evaluasi dan anggaran) & SI Absensi & \\
\hline
\end{tabular}

Hasil pemetaan pada Tabel 5 tersebut mengacu pada hasil yang disajikan dalam Tabel 3. Pemetaan tersebut dibagi atas 4 kuadran berdasarkan hasil wawancara dan observasi penerapan SI pada organisasi saat ini. Kuadran 1 merupakan kuadran Key Operational, SIMMPEDA merupakan sistem yang saat ini menjadi pendukung keberhasilan organisasi. Kuadran 2 merupakan kuadran Support, SI Absensi saat ini menjadi sistem sangat berharga namun tidak menjadikan bergantungnya kesuksesan organisasi. Kuadran 3 merupakan kuadran Strategic, saat ini organisasi belum mengembangkan aplikasi untuk masa depan. Kuadran 4 merupakan kuadran High Potential, saat ini organisasi memiliki aplikasi SIMMISKIN dan Website yang dapat dikembangkan oleh organisasi menjadi salah satu Website yang bisa menyediakan data dan informasi public. Selain itu, SIMMISKIN dapat di integrasikan dengan pihak ketiga, salah satu manfaatnya agar pihak ketiga dapat menyalurkan Tanggung jawab Sosial Perusahaan (CSR).

Hasil matriks Mc Farlan Strategic Grid digunakan untuk pemetaan aplikasi sistem informasi pada BARENLITBANGDA di masa mendatang. Portofolio pada Tabel 6 menggambarkan pemetaan yang dapat mempermudah menentukan prioritas penerapan strategi sistem informasi pada organisasi yang sesuai dengan kebutuhan saat ini dan di masa mendatang.

Tabel 6. Tabel portofolio SI mendatang berdasarkan Mc Farlan Strategic Grid

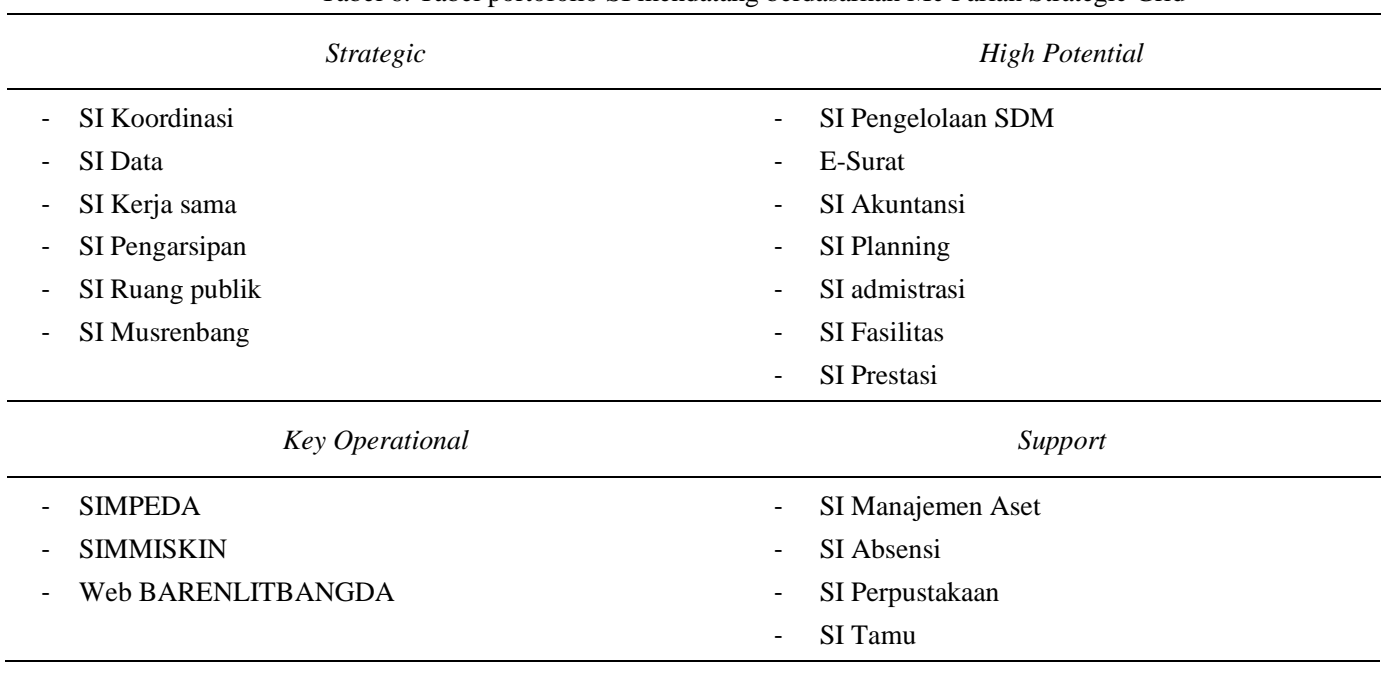

Kuadran Key Operational merupakan kuadran dengan aplikasi yang saat ini menjadi keberhasilan organisasi dan memberikan kemudahan pada aktivitas utama yang dilakukan oleh BARENLITBANGDA, dengan demikinan kuadran Key Operatinal ditentukan dengan melihat aktivitas utama dalam menjalankan organsiasi. 
Kuadran High Potential merupakan aplikasi-aplikasi yang bukan hanya dianggap penting bagi proses kinerja internal, tetapi untuk menunjang aktivitas ekternal juga. Sistem informasi pada kuadran High Potential merupakan pemetaan aplikasi yang ditentukan dari aktivitas pendukung organisasi yang dapat menjalankan kelangsungan proses kinerja organisasi di masa yang akan datang. Kuadran Strategi merupakan aplikasi yang rentan dan sangat berpengaruh terhadap proses kinerja dalam meningkatkan kualitas organisasi di masa mendatang. Dengan demikian kuadran ini ditentukan dengan melihat pentingnya pengaruh sistem informasi yang menjadi strategi untuk meningkatkan dan mempertahankan kesuksesan organisasi. Kuadran Support merupakan aplikasi yang mempunyai nilai berharga dalam menjalankan aktivitas pendukung dalam organisasi, namun keberadaan aplikasi ini tidak menjadikan ketergantungan kesuksesan organsiasi, sistem informasi ini ditentukan dengan melihat aktivitas pendukung yang membutuhkan aplikasi dalam proses kinerjanya agar menjadi lebih efektif dan efisien.

Pemetaan Mc Farlan pada Tabel 6 selanjutnya digunakan untuk melakukan analisis kesenjangan aplikasi digunakan untuk menentukan kebutuhan di BARENLITBANGDA. Analisis ini digunakan untuk menentukan usulan aplikasi apa saja yang akan di upgrade, delete dan planning oleh BARENLITBANGDA seperti pada Tabel 7. Tabel 7 berisi tentang kesenjangan aplikasi yang akan diterapkan BARENLITBANGDA. aplikasi yang saat ini sudah dikembangkan organisasi akan di upgrade dengan meningkatkan integrasi sistem, agar sistem tersebut berpengaruh dengan sistem lainnya. Planning merupakan daftar aplikasi yang belum diterapkan organisasi untuk nantinya dapat di implementasikan organisasi.

Tabel 7. Tabel analisis kesenjangan aplikasi

\begin{tabular}{|c|c|c|c|}
\hline Aplikasi & Upgrade & Delete & Planning \\
\hline SIMPEDA & $\mathrm{V}$ & - & - \\
\hline SIMMISKIN & $\mathrm{V}$ & - & - \\
\hline Web BARENLITBANGDA & $\mathrm{V}$ & - & - \\
\hline SI Absensi & V & - & - \\
\hline SI Akuntansi & - & - & V \\
\hline SI Pengelolaan SDM & - & - & V \\
\hline SI Manajemen Aset & - & - & V \\
\hline SI Pengarsipan & - & - & V \\
\hline E-Surat & - & - & V \\
\hline SI Musrenbang & - & - & V \\
\hline SI Fasilitas & - & - & V \\
\hline SI Perpustakaan & - & - & V \\
\hline SI Prestasi & - & - & V \\
\hline SI Adminstrasi & - & - & V \\
\hline SI Ruang Publik & - & - & V \\
\hline SI Tamu & - & - & V \\
\hline SI Koordinasi & - & - & V \\
\hline SI Data & - & - & V \\
\hline SI Kerja Sama & - & - & V \\
\hline
\end{tabular}




\subsection{Rencanan Implementasi}

Berdasarkan hasil dari usulan portofolio aplikasi dan kesenjangan aplikasi pada BARENLITBANGDA yang sesuai dengan kebutuhan solusi SI yang akan datang, tahap selanjutnya adalah menyusun rencana pengembangan atau implementasi dari hasil tersebut. Hal ini dilakukan dengan memetakan rencana prioritas pengembangan dalam kurun waktu empat tahun yang akan datang berdasarkan kebutuhan SI yang diprioritaskan oleh BARENLITBANGDA, sebagaimana dapat dilihat pada Tabel 8.

Tabel 8. Tabel rencana implementasi SI pada BARENLITBANGDA

\begin{tabular}{|c|c|c|c|c|}
\hline Aplikasi & 2019 & 2020 & 2021 & 2022 \\
\hline SI Pengelolaan SDM & High & & & \\
\hline E-Surat & Potential & & & \\
\hline \multicolumn{5}{|l|}{ SI Akuntansi } \\
\hline \multicolumn{5}{|l|}{ SI Planning } \\
\hline \multicolumn{5}{|l|}{ SI Admistrasi } \\
\hline \multicolumn{5}{|l|}{ SI Fasilitas } \\
\hline \multicolumn{5}{|l|}{ SI Prestasi } \\
\hline SI Koordinasi & & Strategic & & \\
\hline \multicolumn{5}{|l|}{ SI Data } \\
\hline \multicolumn{5}{|l|}{ SI Kerja sama } \\
\hline \multicolumn{5}{|l|}{ SI Pengarsipan } \\
\hline \multicolumn{5}{|l|}{ SI Ruang Public } \\
\hline \multicolumn{5}{|l|}{ SI Musrenbang } \\
\hline SIMPEDA & & & Key & \\
\hline SIMMISKIN & & & Operational & \\
\hline \multicolumn{5}{|l|}{ WebBARENLITBANGDA } \\
\hline SI Manajemen Aset & & & & Support \\
\hline \multicolumn{5}{|l|}{ SI Absensi } \\
\hline \multicolumn{5}{|l|}{ SI Perpustakaan } \\
\hline SI Tamu & & & & \\
\hline
\end{tabular}

Tabel 8 menjelaskan tentang rencana implementasi aplikasi pada BARENLITBANGDA Kabupaten Semarang. Pada tahun 2019 implementasi fokus pada kuadran High Potential karena aplikasi-aplikasi tersebut dapat meningkatkan kualitas SDM dan aktivitas pendukung. Peningkatan kualitas SDM dapat mempermudah dalam mengembangkan rencana implementasi pada tahun berikutnya. Implementasi pada tahun 2020 fokus pada membuat sistem informasi pada kuadran Strategi, organisasi akan lebih siap dalam meningkatkan aplikasi yang rentan terhadap aktivitas utama organisasi di masa depan, karena di tahun sebulumnya SDM sudah dipersiapan untuk meningkatkan kualitas dalam pengelolaan SI/TI. Tahun 2021 mengembangkan aplikasi yang sudah digunakan oleh organisasi, dengan rencana implementasi kuadran Key Operational ini pada tahun ketiga, aplikasi tersebut akan diupgrade agar lebih mudah dan berkualitas. Tahun 2022 akan mengimplementasikan kuadran support, aplikasi yang berharga untuk membantu meningkatkan aktivitas pendukung agar lebih efektif dan efisien. 


\section{Kesimpulan}

\subsection{Simpulan}

Hasil penelitian yang dilakukan dengan menggunakan metode Ward and Peppard pada BARENLITBANGDA Kabupaten Semarang menghasilkan kesimpulan bahwa organisasi dari objek penelitian memiliki kekurangan dalam pengelolaan SDM, manajemen SI/TI, integrasi sistem, dan pemanfaatan potensi-potensi yang ada di lingkungan organisasi. Penelitian ini menghasilkan strategi organisasi dalam mengelola manajemen organisasi dan manajemen SI/TI, organisasi juga memerlukan penekanan dalam menerapkan pengelolaan SDM yang lebih berkualitas yang mampu berkompetisi, dan manajemen SI/TI untuk menunjang aktivitas utama dan aktivitas pendukung. Solusi sistem informasi yang dipetakan dengan portofolio aplikasi organisasi dapat diterapkan dalam kurun waktu 4 tahun (2019-2022), sehingga dapat meningkatkan kualitas organisasi dalam penerapan SI/TI dan mendukung pencapaian visi misi BARENLITBANGDA Kabupeten Semarang.

\subsection{Saran}

Saran yang bisa disampaikan untuk penelitian selanjutnya adalah penelitian selanjutnya melakukan analisa dan mengidentifiksai atau mengaudit perangkat keras yang digunakan dalam mendukung proses bisnis. Dengan menguji kecepatan dan kapasitas perangkat keras dapat menambah poin untuk kelancaran dalam memenuhi tugas dan tanggungjawab organisasi.

\section{Daftar Rujukan}

[1] T. Krista and T. Johan, "Perencanaan Strategis Sistem Informasi dalam Meningkatkan Keunggulan Kompetitif Menggunakan Metode Ward \& Peppard (Studi Kasus: SMK Diponegoro Salatiga)," Repository Universitas Kristen Satya Wacana, May 2014. [Online]. Available: http://repository.uksw.edu/handle/123456789/8776 . [Accessed Jan. 3, 2019].

[2] S. Ketut, "Analisis Realisasi Program Badan Perencanaan Pembangunan Daerah (Bappeda) Kabupaten Buleleng Melalui Pengukuran Value for Money," jurnal pendidikan ekonomi, vol. 1, no. 1, 2013.

[3] Republik Indonesia, instruksi presiden nomor 3 tahun 2003 tentang kebijakan dan strategi nasional pengembangan e-government. Jakarta, 2003.

[4] W. John and P. Joe, Strategic Planning for Information Systems (3rd ed.), Sidney: John Wiley \& Sons, 2002.

[5] K. Abdul, "Pengenalan Sistem Informasi Edisi Revisi," ISBN 9792921583, 2014. [Online serial]. Available: http://eprints.utem.edu.my/13010/1/SI.pdf . [Accessed Jan. 5, 2019].

[6] I.F. Rida, "Analisa Perencanaan Strategi Sistem Informasi Dan Teknologi Informasi (SI/TI) Dengan Menggunakan Framework Ward \& Peppard Di Perguruan Tinggi ABC," Seminar Nasional Sistem Informasi Indonesia, 61-67, September 2014. [Online serial]. Available: http://is.its.ac.id/pubs/oajis/index.php/home . [Accessed Feb. 15, 2019].

[7] D. Wandikbo and M. N.N Sitokdana, "Perencanaaan Strategis Sistem Informasi di Yayasan Binterbusih Semarang Menggunakan Ward and Peppard," Seminar Nasional Inovasi dan Aplikasi Teknologi di Industri, vol. 5, no. 2, February 2019. [Online serial]. Available: https://ejournal.itn.ac.id/index.php/seniati/article/view/2291 . [Accessed Aug. 25, 2019].

[8] S. Yosep, "Perencanaan Strategis Sistem Informasi Dengan Pendekatan Ward and Peppard Model (Studi Kasus: Klinik INTI Garut)," Jurnal Wawasan Ilmiah, vol. 5, no. 2, 2017.

[9] M. Maryani and D. Suparto, "Perancangan Rencana Strategis Sistem Informasi dan Teknologi Informasi (SI/TI): Studi Kasus STMIK XYZ," CommIT, vol. 4, no. 2, 2010.

[10]W. Ari, "Langkah-langkah Perencanaan Strategis Sistem Informasi Dengan Menggunakan Metode Ward and Peppard," Jurnal Sistem Informasi (JSI), vol. 1, no. 1, 2009.

[11]K. Rina, "Perencanaan Strategis Sistem Informasi di Dinas Perhubungan Dengan Menggunakan Metode Ward and Peppard," Jurnal Algoritma, vol. 15, n0. 1, p. 7 - 13, july 2018. Available at: http://journal.sttgarut.ac.id/index.php/algoritma/article/view/120 . [Accessed Jan. 25, 2019].

[12]H. Dedeng and H. Ana, "Perencanaan Strategis Sistem Informasi Dalam Usulan Rencana Pembangunan Jangka Menengah Daerah di Badan Perencanaan dan Pembangunan (Bappeda) Kabupaten Subang," JTK3TI, vol. 2, no. 2, 2017.

[13] M. Raudhah, M.M Palmarudi, and N.T. Andi, "Pengaruh Orientasi Kewirausahaan Terhadap Daya Tahan Hidup Usaha Mikro Kecil dan Menengah Kelompok Pengolahan Hasil Perikanan di Kota Makassar,” Jurnal Analisis, Vol. 6 No. 2, 2017.

[14]D.S.S Boas and R. Yani, "Perencanaan Strategis Sistem Informasi Pada Perusahaan Konsultan Bangunan Menggunakan Metode Ward and Peppard (Studi Kasus: CV. Bumi Cipta Jaya Selaras),” Repository Universitas Kristen Satya Wacana, February 2016. [Online]. Available: https://repository.uksw.edu/handle/123456789/11501 . [Accessed Jan. 3, 2019].

[15]R. Freddy, “Analisis SWOT: Teknik Membedah Kasus Bisnis Cara Perhitungan Bobot, Rating dan OCAI," PT. Gramedia, 2013. [Online]. Available: https://openlibrary.telkomuniversity.ac.id/ . [Accessed Jan. 27, 2019]. 
